\title{
EL HOMBRE, REALIDAD DE REALIDADES: PARA UNA REVALORACIÓN DENTRO DE LA ANTROPOLOGÍA FILOSÓFICA
}

\author{
Carlos Sierra Lechuga \\ Instituto de Filosofía \\ Pontificia Universidad Católica de Valparaíso, Chile \\ rideo_ergo_sum@hotmail.com
}

Resumen

Una de las interrogantes típicamente filosóficas ha sido la que pregunta por el hombre. Si bien desde antaño se ha tratado la cuestión filosóficamente, no se ha hecho, sin embargo, sólo filosóficamente. Para saber qué o quién es el hombre han investigado diversas disciplinas y ciencias. Este artículo sugiere la base para pensar o repensar al hombre en clave metafísica, allende la clave que lo piensa, primariamente, desde su animalidad. La antropología filosófica debe ser, ante todo, filosófica, por lo que debe justificarse desde sí misma.

Palabras clave: animalidad, antropología filosófica, Heidegger, hombre, realidad. 


\section{Man, Reality of Realities: for a Reassessment Within the Philosophical Anthropology}

Abstract

One of the typical philosophical questions is that which asks for man. Since ancient times, the issue has been addressed philosophically; however, not only philosophically. Several disciplines and sciences have investigated in order to find out what or who is man. This paper suggests the basis to think or rethink man in a metaphysical key, beyond those keys that think him, primarily, from his animality. Philosophical anthropology should be, over all, philosophical, therefore it has to be justified by itself.

Keywords: Animality, Heidegger, Man, Philosophical Anthropology, Reality. 


\section{Introducción}

¿Animal racional, animal político, social, simbólico? Animal, siempre por el camino de lo animal. Animal no entendido ya como poseedor de anima, como un $\zeta \hat{\omega} o v$, un viviente, menos como aquel que tiene $\psi v \chi \eta \dot{\eta}$, sea de cualquier clase. Hoy en día y, en general, se entiende al animal como reino taxonómico de la biología actual, el animalia; clasificación en la que entran aquellos organismos eucariotas (que poseen células con núcleo bien definido), heterótrofos (en cuya nutrición las sustancias orgánicas como el carbono y el nitrógeno son sintetizadas por otros organismos diferentes de sí), pluricelulares (cuyas funciones vitales se constituyen en más de una célula) y tisulares (cuyas células están organizadas de manera tal que forman tejidos), tipificados además por una locomoción autónoma (su movimiento no está puesto directamente en función de agentes externos), plan corporal (disposición interna de los órganos, tejidos, etc., en simetrías y segmentos corporales), etc. La animalidad se ha dicho de muchos modos a lo largo de la historia del pensamiento occidental, pero hoy en día se dice según el discurso de las ciencias biológicas.

Se ha dicho, como indico, de muchos modos, por mencionar algunos ejemplos que, a mi parecer, han pensado la animalidad siguiendo entre sí más o menos la misma estela. Diré para ilustrar que Hegel la pensó en lo orgánico como la esfera del ser-para-sí, en la que los singulares se relacionan con lo singular como tal dándose ahí el primer estrato real en el que existe individualidad, el animal es "la vida que existe como vida” (Hegel, 2008: p. 124) y para el cual la cosa es en el ser, a diferencia del Espíritu en el que la cosa misma es; por su parte, Bergson distinguió la animalidad de la humanidad en función de las divergencias y convergencias que él había encontrado entre instinto e inteligencia, estando el primero más cerca de la vida que la segunda, pero siendo la segunda más universalista a pesar de frenar la realidad vital (Bergson, 2007); y Zubiri ha matizado que el animal en general formaliza las cosas con que se encuentra solamente como meros estímulos y no como el hombre, que con su inteligencia (sentiente) las formaliza como realidades de suyo, de modo tal que 
- por ejemplo- el calor no sólo calienta sino que además es caliente (Zubiri, 1980). De alguna manera, para ellos la humanidad es un caso extra-ordinario de la animalidad; estos tres ejemplos nos dicen que el animal tiene una relación con el mundo muy otra que la que tiene el hombre: según uno, para el animal las cosas no son sino que están en el ser, según otro el animal conoce las cosas mismas y no tanto las relaciones que hay entre ellas, y según el último el animal sólo siente estímulos y no así realidades. Lo que es claro es que, sean como sean los modos como se dice la animalidad, la humanidad quiere decirse específicamente de otro modo.

Muchas de las conceptuaciones que han intentado hacerse del hombre para garantizarlo como algo diferente o, más bien, específico, dentro de la totalidad de lo real han querido trascenderlo de su correlato biológico, sin embargo, no cesan de llamarle animal. ¿Se le llama animal para mostrar que efectivamente lo es pero que también es algo más que un mero animal? Si es el caso, también podríamos llamarle meramente "compleja estructura basada en carbono 'racional', 'política', etc.”. Por otro lado, llamándole animal para mostrar

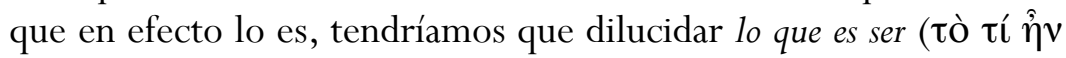
Eîval) ${ }^{1}$ animal, es decir su esencia, tendríamos por tanto que insertarnos en todo eso que es ser animal y luego tener un extra, un plus, que ya no sea meramente animal ni tampoco reducible a ello; pero, aun siendo el caso, al conceptuarlo como un animal que es algo más que lo animal, parece que el polo discriminatorio de lo que es ser humano sigue estando focalizado en lo animal. Si no se tratara de subrayar su animalidad como una suerte de núcleo -aun cuando sí sea un animal- ¿por qué conceptuarlo de entrada como animal?²

1 Literalmente: lo que era ser.

2 Max Scheler me parece un caso ejemplar de esto, si en su propuesta afirma que lo humano -que es el espíritu- no es propiamente biológico, me parece que no tiene argumentos contundentes para que eso que él llama espíritu no sea una pura consecuencia de la complejidad biológica (una propiedad emergente capaz, incluso, de generar causalidad up-down). De hecho, tanta dedicación e importancia desmedida a lo que la biología puede decir del hombre, me hace pensar que él considera a la ciencia como ese inamovible parámetro discriminatorio que distingue lo que es $x$ y lo que no (Scheler, 2000). 
¿O es que se le llama al hombre, ante todo, animal, para mostrar únicamente que es un tipo concreto de animal? Si esto es así, si es el hombre un modo concreto de ser animal, entonces el apellido de lo animal (sea racional, político, simbólico, etc.), no es más que una etiqueta taxonómica, equivalente a la de sapiens (que acompaña al género homo). Si es así, decía, la ciencia dedicada el estudio de este concreto animal no es la antropología - mucho menos la antropología filosófica- sino, más bien, la zoología, la anatomía comparada, la taxonomía, la etología, la mera biología; o, en todo caso, sería una antropología nivelada a la conquiliología o a la ornitología, entre otras, estudiando al hombre como se estudia a los moluscos o a las aves.

¿Qué quiere decirse del hombre cuando se le dice animal? ¿Se trata de una actitud en la que el hombre se reconoce siendo una parte más, no esencial, en el devenir del mundo natural? ¿Se trata de humanizar lo natural como si el ser humano dignificara el ser animal? ¿O se trata, a mi juicio atrozmente, de animalizar al hombre? Trataré de dar algunas luces al respecto en cinco movimientos: primero, distinguiré brevemente los límites de lo abordable científicamente a fuer de clarificar los juicios sobre el hombre; luego, habré de señalar que mientras que el sujeto del juicio permanezca siendo "animal", poco importa el adjetivo que lo califique; en función de lo dicho, tendré que hablar desde la metafísica de un aspecto que considero garante de la especificidad del hombre; asimismo, uniendo esto último con lo anterior, habiendo mostrado la especificidad del hombre, podré clarificar su diferencia; concluiré, por último - no sin antes señalar un par de puntos en la antropología heideggeriana que me resultan criticables a este respecto-, con algunas consecuencias éticas de pensar (o repensar) al hombre en clave metafísica.

\section{Distinción de lo que es abordable científicamente para una clarificación de los juicios sobre el hombre}

Hay algo claro: el hombre es diferente al resto del mundo. Pero ¿cuál es el modo de ser de su diferencia? ¿Qué es lo que vuelve diferente su diferencia?, pues está claro que una piedra también es diferente al 
resto del mundo. Se ha respondido, desde antaño, que su específica diferencia está en la inmediatez consigo mismo, en su autorreferencia, etcétera, pero la verdad es que éstas son preguntas nada fáciles de contestar a las que toda respuesta ha parecido insuficiente. Las ciencias han intentado lo propio, pero si bien ellas pueden ayudarnos a cuantificar y comparar la concretitud humana, me parece que es labor filosófica la de enjuiciar cualquier resultado; es decir, de cara a la pregunta por el hombre, los resultados científicos son resultados que requieren de una interpretación metacientífica (o al menos extra-científica) que abarque las consecuencias e implicaciones no dadas de facto en los propios resultados científicos; o lo que es lo mismo, que frente a una pregunta tal, los resultados científicos necesitan conclusiones filosóficas y no ya científicas. Siendo esto el caso, entonces considero que el apelativo de "animal" no es el adecuado como concepto liminar del hombre.

Cuando el científico cientificista dijera: "el hombre es un animal diferente al resto de los animales, sí, pero lo es al modo como la libélula es también diferente", afirmando que el hombre es concretamente un animal humano mientras que la libélula concretamente un animal libelulezco, es decir, que uno es animal al modo homínido y específicamente humano, mientras el otro al modo anisóptero y específicamente libelulezco; cuando afirmara ello, estaría afirmando que si bien el hombre es diferente, su diferencia estaría en ser animal al modo humano y no libelulezco, ni tigrezco, ni chimpancezco, etc. De tal forma que su especificidad no sería más que una taxonómica o, incluso, si se quiere, fisiológica; pero estribaría tan sólo en el modo de organización material de los elementos que lo componen, modo de organización que -aunque complejo-es, a la postre, accidental. De esta suerte, si para esos animales que viven su animalidad de modo insectivo existe la entomología, entonces para esos otros animales que viven su animalidad no ya homínidamente sino humanamente, existe la antropología. ¿Será acaso que cuando la antropología se pretende ciencia se zoologiza, escondiendo tras un afán de objetividad y rigor un motivo de animalización de lo humano, viendo en las sociedades no más que una complejización de las 
colmenas de abejas o las colonias de termitas? ${ }^{3}$ Cuando el científico cientificista afirmara, de alguna manera, que la antropología es una rama de la zoología, siendo ésta una de la biología, su afirmación sería deducida de un enjuiciamiento del hombre como siendo diferente accidentalmente pero no esencialmente; mas esta clase de juicios -como hemos dicho-son filosóficos, no ya científicos, y el paso de los resultados científicos a las conclusiones filosóficas debe estar cuidadosa y finamente justificado, si no, devienen juicios ideológicos. Por su parte, el científico (no-cientificista) se contentará con decir que sus resultados sugieren que el hombre sea un animal preciso, mientras que el cientificista - esto es, aquel que ha confundido los resultados científicos con las conclusiones filosóficas, o lo que es lo mismo, el ideólogo de la ciencia- se excederá diciendo, partiendo de lo que los resultados sugieren, que el hombre es sólo un animal preciso. Las posturas extra-científicas deben justificarse extra-científicamente. Así pues, la conclusión ontológica en la que se dice lo que el hombre es a partir de tales o cuales resultados científicos, es una conclusión dicha desde una postura filosófica, por lo que si no está justificada ni diferenciada puede devenir ideología. ${ }^{4}$

Por ello, decía que las ciencias nos ayudan a saber las diferencias humanas abordables científicamente respecto de aquello que también es abordable científicamente; y en eso podrán decirnos lo que de manera científica es el hombre. Pues efectivamente, el hombre posee alguna propiedad que puede abordarse científicamente, por ejemplo el cuerpo (que no su cuerpo, cada cuerpo es vivido subjetivamente y es, por ello, inabordable desde la ciencia). Por su parte, la propiedad del hombre de poder abordar científicamente alguna

3 Sobre este tema es importante mirar la crítica buberiana a la antropología en general (Buber, 2008). Por otro lado, recuérdese que "antropología" no es lo mismo que "antropología filosófica". La primera parece estudiar los productos humanos dando por supuesto lo que es el hombre, la segunda intenta dilucidar propiamente eso que se da por supuesto en la antropología, a saber, qué es el hombre (a mi modo de ver, la antropología filosófica no debería preguntar siquiera por qué es el hombre sino por quién es el hombre).

4 Las ciencias tienen un modo preciso de proceder que no tendría por qué ser violado por confusión alguna (Sierra Lechuga, 2013a, pp. 180-184 [el apartado intitulado Edificación]). 
propiedad suya no es una propiedad a su vez científicamente abordable, pues ésta trasciende el conocimiento de orden científico y, más bien, queda presupuesta en él como conditio sine qua non. Con ello, es claro que hay propiedades del hombre que escapan de la competencia de las proposiciones científicas. Así pues, frente a las propiedades humanas trascendentes respecto de lo científico, la ciencia no puede manifestar especificidad ni diferencia humana alguna, porque de hecho ello escapa a su jurisdicción no pudiendo manifestar juicio acientífico alguno.

\subsection{Excursus}

Decía del cuerpo humano que es una propiedad científicamente abordable en cuanto que es objetivable como el cuerpo (a diferencia del cuerpo propio, su cuerpo). Sin embargo, esto que es científicamente abordable no tiene que ser lo definitorio del hombre -al menos no por principio-, pues que el hombre "posea" de algún modo un cuerpo no lo hace ser un cuerpo, sino que en todo caso lo haría ser corpóreo - que no es lo mismo. Sirva lo dicho para pronunciarme sobre un tópico hoy de moda en muchos núcleos intelectuales y hablar, verbi gratia, del cerebro: el que un tal órgano le sea fundamental al hombre no implica que aquello que le es fundamental sea su fundamentalidad misma: el que el hombre se vea severamente desvalido sin su cerebro no hace del hombre ser un cerebro, más bien, y tan sólo, ser un hombre cerebral; fundamentalmente cerebral, si se quiere, pero no fundamentalmente un cerebro. ${ }^{5}$ La fundamentalidad de algo está constituida por propiedades fundamentales, pero tales propiedades fundamentales no son ellas mismas la fundamentalidad.

5 Sobre esto mismo he versado en otro sitio en torno a la conversión religiosa: “Creyente no es el cerebro, creyente es el complejo íntegro y ontológicamente estructurado que llamamos persona. Persona que no es que tenga un cerebro, ni que sea un cerebro, sino que es cerebral. Persona no es un cerebro encubetado (envated brain), y por ello decimos que la conversión no es cerebral sino personal. La conversión es personal no sólo porque sea mía, sino porque soy yo como totalidad personal quien me convierto" (Sierra Lechuga, 2013a: p. 174). 
Esto será afortunadamente preclaro para lo que querremos decir luego, pues la animalidad del hombre podrá ser lo fundamental que se quiera, pero ello no implica que la animalidad sea la fundamentalidad humana.

\section{Mientras que el sujeto permanezca siendo "animal", poco importa el adjetivo que lo califique}

Sin embargo, no son sólo los científicos cientificistas los que podrían afirmar del hombre ser un animal $x$, sino incluso también ciertos filósofos, psicólogos y antropólogos. ${ }^{6}$ Éstos, aunque pretendidamente esperan encontrar lo específicamente humano, no dejan de ver en el hombre algún tipo - quizá sofisticado- de animal, y si bien la dimensión $x$ de dicha animalidad que tal pensador ha propuesto les parece "reduccionista" respecto de lo que ellos consideran que debería ser el hombre, pretendiendo llevar esa dimensión suya hasta la y, z o w, todas estas dimensiones continúan como predicados o calificativos de lo animal.

Si hacemos caso a que la oúoí $\alpha$ es aquello que no se predica sino aquello de lo que se predica, y que la ov̉oía es esa realidad primaria, propia e independiente por sí, suficiente y delimitada ( $x \alpha \theta$ ' $\alpha v \tau o ́$ y $\pi \varepsilon ́ \varrho \alpha \varsigma)$, que es la llamada "sustancia” a la que se le atribuyen accidentes ( $\sigma v \mu \beta \varepsilon \beta \eta x$ ó $\alpha$, i.e. acompañantes), y -por otro lado- cada vez que decimos del hombre ser un animal $x$ predicamos $x$ de la animalidad pero dejamos incólume a la animalidad misma, entonces implícitamente estamos diciendo que la oủoí $\alpha$ del hom-

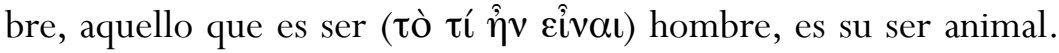

6 Por supuesto, no todos los filósofos ni antropólogos empiezan conceptuando al hombre por su animalidad, por lo que la crítica se dirige sólo a quienes sí empiezan por ahí. Aristóteles (animal racional y político -sólo si aceptamos que $\zeta \hat{\omega} o v$ significa "animal" y no -como yo preferiría por su sentido griego- "viviente"), Marx (animal social), Freud (animal pulsional), Cassirer (animal simbólico), incluso Zubiri (animal de realidades), Baumeister (animal cultural), son ejemplos de pensadores que ven la animalidad del hombre como su foco. Aun cuando la animalidad a la que puedan referirse algunos de ellos no sea la del discurso biológico (o biologicista), mutatis mutandis, ¿por qué de entrada llamarle animal? 
Visto así, ser animal es lo más real (oủoía) del hombre, su esencia

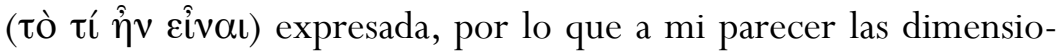
nes $x, y, z$ a donde sea llevada su animalidad son, a la postre, meros

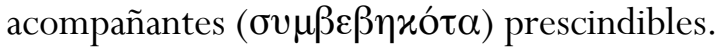

Personalmente, creo que no importa qué tantos adjetivos o qué tanta carga semántica se le dote al adjetivo que acompañe a lo animal, pues el sustrato de fondo (el sujeto) sigue siendo la animalidad misma. Siguiendo la línea de este artículo, los pensadores que hablan así, sépanlo o no, son de algún modo cientificistas; pues efectivamente siguen nombrando animal a aquello que va allende lo animal y que no tendría por qué ser nombrado por principio "animal” más que por una precomprensión que precomprenda a las ciencias -sean éstas la contemporáneas, sean las de cada tiempo-como conocimiento primero. ¿Por qué comenzar la definición del hombre por el lado de su animalidad es precomprender como primero al discurso científico? Porque para nombrar a algo "animal" hay que saber a qué se le llama animal, es decir, tratar con el discurso que versa sobre la animalidad misma, recurrir a la biología en general (o a su equivalente en cada caso histórico); es ahí donde vuelve a insertarse la idea de que el factor crucial en la diferencia humana lo da o dará la ciencia. Es verdad, biológicamente somos animales, es decir, aquella propiedad humana abordable por la ciencia (biológica) es una propiedad efectivamente animal, somos la especie homo sapiens de la familia de los homínidos del orden de los primates de la clase de los mamíferos del phylum de los cordados del reino animal; clasificados en él por ser, como el resto de los animales, organismos eucariotas, heterótrofos, pluricelulares, tisulares, poseer una locomoción autónoma, entre otras propiedades más. Pero biológicamente parece que nuestra diferencia sólo está a nivel de complejidad o de especificidad, como la libélula es diferente por ser libélula, pues no está claro de ningún modo que nuestra inteligencia -si es de raigambre biológica- sea algo mayor (sino en todo caso algo meramente específico) que la velocidad del guepardo o la adaptabilidad de las bacterias. ¿Será que la especificidad humana sólo puede ser concebida como un nivel de organización o grado de complejidad de lo vivo en general y de lo animal en particular? ¿O será que la especificidad humana es repetible por 
otra especie, por ejemplo, aguardando unos miles de años para que otros ciertos primates alcancen el grado de evolución que nosotros tenemos actualmente - como si fuese posible al menos una teleonomía biológica local? Esto es, ¿será que la especificidad humana no es específica, sino tan sólo una variable contingente y/o reproducible dentro del juego iterativo de la evolución? ¿O será acaso que el hombre es una ocurrencia accidental del mundo natural, y por tanto una pura animalidad, tan accidental como podría ser la vida misma tras un mero juego entre el azar y la necesidad (Monod, 2000)? Estas preguntas aparecen cuando en las premisas con las que se comienza la conceptuación del hombre está la de "animal x".

A mi particular parecer, me parecen vanos los esfuerzos de los filósofos o antropólogos por definir al hombre como animal $x$, y por tanto vanas sus luchas por el mejor apellido posible, que si no es animal político sino social - como señala Marx a Aristóteles (Marx, 1982: p. 263)-, que si no es animal racional sino simbólico - como señala Cassirer a toda la tradición filosófica en general (Cassirer, 2001: p. 49)-, etc., pues todos ellos precomprenden que lo efectivamente animal del ser humano es un factor clave en la especificidad de su diferencia humana. Se discute qué clase de animal es, pero no se discute que sea animal. Todos ellos dan una importancia crucial, de una u otra manera, al cientificismo. El hombre es un animal, es cierto, pero ¿puede su especificidad animal explicar que sea el único que categorice al resto de los animales, que se incluya a sí mismo dentro de una de esas categorías, que note las diferencias sutiles entre lo vivo y no vivo y entre lo propio de este o aquel animal? ¿Es parte de su especificidad animal el caer en la cuenta de las especificidades animales incluida la suya? Posiblemente, pero aventurar respuestas a priori a la investigación es poco científico, ${ }^{7}$ y los datos hasta hoy obtenidos no nos permiten aventurar respuesta alguna. En cualquier caso, el animal capaz de ordenar taxonómicamente, de entender fisiológicamente, de conocer las diferencias precisas entre el resto de los animales, de abordar cognitivamente a cualquier otro animal es un

7 Pues la respuesta es una toma de posición ( $\theta \varepsilon \dot{\sigma} \iota \varsigma)$. No se confunda, pues, el aventurar

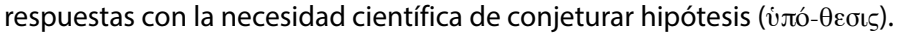


animal diferente y, en este sentido, es un animal que anda por encima del resto de los animales, esto es, que tiene por propiedad esencial el andar por encima.

"Por encima" porque puede abarcarlos a todos. ${ }^{8}$ Puede asir, siquiera conceptivamente, la totalidad. ${ }^{9}$ Un animal que anda por encima de todos los animales sugiere, a mi modo de ver, no ser un animal o, mejor dicho, no ser nuclearmente un animal, pues ¿por qué gozaría de ese poder abarcante un mero animal? ¿Un animal que anda por encima del resto, sigue siendo stricto sensu un animal? Sin duda, es físicamente posible que así sea (pues así como el hombre es facultativamente abarcante, el guepardo es facultativamente veloz), pero es metafísicamente distintivo el que de hecho así sea: quizá habrá que comenzar a conceptuar a ese animal que anda por encima de lo animal no ya como un animal, al menos no conceptualizarlo así de entrada; y decir, por lo tanto, no únicamente que "el hombre no es sólo un animal", sino además decir explícitamente que su ser animal no es específicamente distintivo de su ser humano. De hecho, justamente, su ser animal no lo distingue del resto de lo animal sino que, como parece obvio -y por lo tanto es dado por obviado y no se ve--, es aquello que lo reúne con el resto de los animales.

8 Remito a la etimología de abarcar: ad brachium, al brazo. Por ello, en la siguiente frase hago énfasis en asir.

9 Podría pensarse que patologías como, por ejemplo, la simultagnosia, contradicen lo aquí dicho al menos en términos especiales. Yo, por mi parte, no lo considero así. En la simultagnosia (que sirve aquí como arquetipo -bien podría ser otro caso-) el individuo es incapaz de aprehender más que un solo objeto a la vez, esto podría significar que al hombre no le es propio (o al menos no a todo hombre) el andar por encima asiendo la totalidad qua totalidad. Empero, esta propiedad es una propiedad formal, es decir, aquello que se aprehende es aprehendido formalmente como real-como en breve indicaremos- y como total, esto es, como una totalidad real. Esto implica que, aun cuando el individuo con simultagnosia no vea más que un objeto en particular, tal objeto le aparece como una unidad, esto es, como totalidad; si bien este individuo no puede ver escenas completas, aquel elemento que capta individualmente es para sí una suerte de "escena completa": si no ve más que a una persona y no a todo el auditorio, esa única persona es aprehendida formalmente como una unidad, aprehende a la persona como totalidad y no como brazos, piernas, etc., apelmazados; lo mismo si aprehendiera sólo un rostro, un ojo o cualquier otro contenido, la formalidad (la forma de lo aprehendido independientemente de su contenido) siempre es como totalidad (y realidad -como en el texto diremos). 


\section{La especificidad del hombre}

Según lo dicho, el hombre es $x$, y luego es animal; y siendo eso que es, encuentra entonces que algo comparte con el resto de los animales. Digo que el hombre anda por encima. Entiéndase que "por encima” no guarda ninguna acepción valorativa, sino más bien realizativa: el hombre anda por encima porque con algo suyo puede abarcar de algún modo a todo el resto; no es sólo que la totalidad del resto se distienda ante el hombre, sino que él, desde sí, puede abarcarla, asirla. ${ }^{10}$ Vayamos sin rodeos: anda por encima porque su realidad le permite aspirar a recubrir la totalidad de lo real; concretamente, puede barrer las demás realidades animales, tanto que incluso las clasifica, las compara, las experimenta, las teoriza, las conoce, las realiza. Aquí realizar no significa que el hombre sea el creador efectivo y ontológico de la totalidad de lo real, ni que nada tenga sentido sin él, ni que ordene fenoménicamente el desorden nouménico, ni que él todo lo organice, ni que sea la medida de todas las cosas; tan sólo significa que cada parte, estructura, elemento, propiedad, etc., de esa totalidad, e incluso la totalidad misma, son para el hombre realidades, realidades que en cuanto le salen al paso, le salen como siendo reales, ${ }^{11}$

10 Esto no implica que el hombre pueda saber o conocerlo todo. Hablamos simplemente de un abarcar, es decir, de un caer en la cuenta, de un fijarse en, recubrir, barrer, de un poner-la-vista-en (de $\theta \dot{c} \sigma ı \varsigma$ y óó́ $\omega$ ): de teorizar ( $\theta \varepsilon \omega \varrho i ́ \alpha)$. La realidad siempre es abierta tanto por su carácter físico (por ejemplo, el principio de incertidumbre), como por su carácter metafísico (en cuanto totalidad, i.e. que cualquier cosa que ocurra -sea lo que sea- será igualmente real gracias a que la realidad es total, si la totalidad no abarcara todo incluyendo la novedad, no sería totalidad; también en cuanto que realidad es mera formalidad inespecífica y sin contenido [Zubiri]).

11 Cito in extenso algo que en otro lugar he dicho a este respecto: "El llamado Realismo no es aquello que usualmente se cree, a saber, aquella doctrina que afirma la independencia de la existencia de las cosas respecto de nuestra inteligencia; si fuese el caso, el Realismo carecería de relevancia, pues ocurriría con él lo mismo que con ese quien, habiendo visto un ave volando, preguntara si es posible que las aves vuelen. El Realismo, muy por otro lado, es la actitud filosófica que cree que aquel objeto de estudio por el que se está preguntando es la realidad del objeto y no la idea que nos hemos forjado de él. Este es un matiz fundamental, pues nadie -al menos nadie grande- negó nunca la existencia de la Realidad, lo que sí hicieron fue distinguir su objeto de estudio, ora creyendo que aquello a lo que se dirigían era la realidad de la cosa ora, por otro lado, la idea de la cosa, conformando, así, escuelas: el Realismo y el Idealismo -por ejemplo, Kant, padre del Idealismo alemán, no negó la realidad de nada, lo que negó fue la 
de tal forma que su realidad queda en él actualizada. Entiendo, pues, aquí por "realizar" el mero actualizar la realidad ínsita de las cosas mismas. Independientemente del contenido de aquello que le sale al paso (digamos, de aquello que le aparece a su conciencia, de aquello que es inteligido por la inteligencia, de aquel percipi percibido por el percipens, etc.), el modo -la forma- en que le sale al paso es en modo real; sea lo que sea que le salga al paso, el hombre lo recibe como siendo real, la aparición misma es real; esto es de alguna manera lo que Xavier Zubiri ha llamado formalidad, la estructura formal es el carácter de realidad, realidad es formalidad de las cosas actualizadas en la aprehensión, es pues un mero "quedar" en la aprehension. ${ }^{12} \mathrm{Al}$ hombre le salen las cosas de forma real, mas si es así se debe a que él es una realidad concreta confrontada en la resistencia de esas realidades: baste de prueba para esto que el hombre tropiece con ellas para caer en la cuenta de que la propiedad real de lo que se expresa -por

imposibilidad de conocer la realidad de nada, que es diferente; en virtud de esto, aunque lo que conocemos es el fenómeno, ni duda le cabe que tras él hay un nóumeno.

"Así pues, la distinción académica entre los llamados Realismos ingenuo y crítico me parece una distinción secundaria. Será lo relevante que se quiera, pero secundaria. Lo fundamental es dejar claro que nadie duda de la propia Realidad, de lo que se duda es que se pueda o no conocer tal y como es. La apuesta del Realismo, así, no es demostrar la Realidad sino especificarla, profundizar en ella, darle un contenido pleno a eso que formalmente llamamos Realidad. Digamos que la pregunta fundamental no es si es posible o no que las aves vuelen sino cómo lo hacen." (Sierra Lechuga, 2013b, pp. 25-26).

12 A lo largo de su obra, Zubiri ha querido dejar claro este punto. Esto no es en modo alguno un resumen, sino un esquema rápido de la tesis zubiriana: la inteligencia (y no conciencia, subjetividad, etc.) tiene por función (acción) primigenia no la resolución de problemas ni la facultad de juzgar, sino la actividad primaria de inteligir, es decir, de aprehender las cosas reales en tanto que reales. Mientras que los estímulos sensibles nos dicen del calor, por ejemplo, que calienta, la inteligencia nos dice, además, que es caliente. La inteligencia tiene un primer momento constitutivo en virtud del cual se llama, sobre todo, inteligencia sentiente; este momento es la impresión de realidad. La realidad, que es inteligida, es sentida en las cosas reales; inteligida y sentida a una. En el contacto que se tiene con las cosas, las cosas nos hacen patente su realidad (a través de su afección [afección real], alteridad [altera ralitas] y su fuerza de imposición [fuerza de realidad]), la realidad suya, o como el mismo Zubiri diría: lo de suyo. En ningún momento la realidad es lo meramente físico, la Realidad es -al menos primariamente- la estructura formal de la aparición de las cosas (sean o no físicas). Lo físico son las talidades, es decir, tales realidades, las cosas tal y como son; pero la talidad se constituye por un contenido concreto y una forma, que es precisamente el carácter de realidad y que, así, no es ya tal sino trascendental (abierto) (Zubiri, 1980; 1981: pp. 41-59; 2001; 2005: pp. 5-7; 2006). 
ejemplo- como gravedad se resiste a su propia realidad física humana; o baste con querer pensar desoccidentalizadamente estando inmiscuido en la historicidad occidental para notar que la propiedad real de las ideas y concepciones se resiste a la propia realidad histórico-cultural humana, etc. (Sierra Lechuga, 2013b; 2013c).

Antes que venirle al hombre su especificidad en ser el animal $x$, o en que sea dador de sentido, en que sea sujeto, en la comunicación intersubjetiva y demás esquematismos, o en la consistencia del mejor argumento posible de "lo que es ser hombre", me parece que su especificidad propia está en la resistencia específica de su ser real respecto de la resistencia de otras realidades. En virtud de su realidad que lo dispone respecto de otras realidades, es que puede abarcar a éstas $a$ pesar de y guiado por cualquier resistencia. Es decir, su especificidad está en ser una realidad concreta a la que la realidad se le resiste manifiestamente en su recubrimiento de otras realidades concretas. El hombre es una realidad que se realiza con otras realidades que también se realizan con su propia realidad, resultando de ello un recreo de realidades concretas que conforma no la consistencia sino la resistencia de la realidad total. Lo que significa que, para el hombre, la realidad antes que ser lógica, no contradictoria, un mero modelo, o siquiera modelable, esto es, la realidad antes que ser consistente, es resistente. De ahí que las realidades concretas limiten los modos de recubrimiento con que son abarcadas por la realidad humana. ${ }^{13}$ Cuando el hombre abarca el resto de la realidad, sin duda hay algo que él atribuye a dichas realidades humanizándolas -como cree el subjetivismo-, pero son las realidades mismas las que acotan aquello que el hombre puede atribuirles - como ya no cree el subjetivismo. Por ello, más que decir que el hombre humaniza al mundo (siendo animal x para "dignificar" lo animal), o que el mundo mundaniza al hombre (siendo animal x para "banalizar" lo humano), digo que el hombre realiza al mundo y éste a aquél (siendo realidad de realidades), constituyendo la realidad como totalidad resistente. El mundo y el hombre están realizándose en su mutua imbricación.

13 Esto es lo que en otro lugar he llamado "Principio de correspondencia ontológicoepistemológico" (Sierra Lechuga, 2013C). 
En tales procesos de realización, el hombre anda por encima, es decir, puede ver la totalidad en perspectiva, y es propiedad suya el andar por encima, pues ésta es quien le permite dar atributos a las otras realidades aunque éstos sean encaminados por sus resistencias. "Realizar” es aquí entonces no sólo el mero actualizar la realidad ínsita de las cosas, sino además el poder abarcar realidades de manera real imbricándose en lo que tienen de reales dichas realidades. Anda por encima porque es una realidad capaz de recubrir realidades. Y recubrir es poder andar por encima, hacerles algo a las realidades concretas pero, sobre todo, a la realidad en su totalidad: abstraerla, matematizarla, dibujarla, esculpirla, entenderla, interrogarla, imaginarla, narrarla, vivirla, durarla, padecerla, y un largo etcétera.

\section{Especificidad y diferencia del hombre}

Si antes que ser realidad de realidades, el hombre fuera primigeniamente un animal, si nuclearmente fuera animal, ¿qué tiene el hombre animal para poder recubrir las otras realidades animales? (Salmo 8, 4-5). ${ }^{14}$ Pensado como animal, el hombre no es en verdad radicalmente diferente. Si nuclearmente fuera un animal, ¿por qué es o existe un animal por encima del resto? Partiendo de su animalidad, es ociosa la búsqueda de su radical diferencia, pues su diferencia no es más que taxonómica, y las diferencias taxonómicas, incluso fisiológicas, serán lo relevantes que se quiera, pero no radicales. ¿Por qué no buscar, en todo caso, la diferencia radical de las libélulas? Si el hombre fuera primigeniamente un animal, ¿por qué la realidad animal se bifurca para "jerarquizar" a sus participantes poniendo al hombre por encima? Está claro que animalmente la jerarquía es siempre relativa, y no hay mayor jerarca que aquel quien gobierne en la red alimenticia, por ejemplo, o quien se adapte mejor al medio, superviviendo como especie. Siendo su oưoía la animalidad, ¿por qué, pues, un animal puede abarcar animales? Quizá todas estas preguntas estén mal plan-

14 "Cuando veo tus cielos, obra de tus dedos, la luna y las estrellas que tú formaste, ¿qué es el hombre para que lo recuerdes, y el hijo del Adán para que lo visites?". 
teadas (parece incluso evidente que así lo están), pero es que todas ellas parten de la premisa del hombre como animal, y partiendo de ella suena ilegítimo (y, por lo tanto, injustificable) hablar del hombre como andando por encima aun cuando, en efecto, lo ande. Por ello, las premisas para plantear esta clase de preguntas deben ser otras. ${ }^{15}$ El hombre es un animal, sí -ni duda cabe--, pero eso nada tiene que ver con su propia diferencia que lo diferencia radicalmente del resto del mundo animal y del mundo no-animal.

Ser animal es fundamental para el hombre, pero no es su fundamentalidad. El hombre, antes que ser animal, sería en todo caso tan sólo animalesco. El hombre como animal sólo es diferente de otros tantos animales por ser un animal humano, y por ello es que parece incomprensible (e incluso absurdo e ilegítimo) por qué puede andar por encima del resto de los animales con su recubrimiento sobre ellos. El hombre es diferente en sentido fuerte no por su animalidad, sino por ser una realidad capaz de poder abarcar realidades (la suya o la que sea, incluso la totalidad de lo real) y, concretamente, por poder abordarlas de forma real. Pongamos por caso un ejemplo: el hombre abarca la realidad del insecto con sus conceptos entomológicos, y la manifestación de la realidad insectiva es una manifestación real, es decir, el hombre no se cree a sí mismo como un diablillo hipotético estudiante de insectos, ${ }^{16}$ no cree tampoco estar estudiando meras ilusiones, no cree, además, que la entomología sea una gimnasia mental; sino que atestigua efectivamente que él es realmente un entomólogo, que el insecto estudiado es real y que su recubrimiento entomológico realmente dice algo de la realidad insectiva. De hecho, el recubrimiento real de la realidad animal es un caso particular del recubrimiento general de la realidad general. Abarcar las otras realidades es realizarlas, en el sentido de que la realidad humana se realiza con otras realidades resistentes que a su vez también se reali-

15 Me parece que por aquí iría una interesante interpretación de los primeros capítulos del Génesis, cuando Dios pone al hombre por en encima del resto de la creación; el hombre como siendo algo particular y especial en el seno divino para no dejarlo a la par del mundo en general.

16 Cfr. Los afamados diablillos de Descartes (Malin génie), de Laplace y Maxwell. 
zan con la resistencia humana. Entendido el hombre como realidad de realidades, la clave desde la que se le mira no es ya cientificista ni científica, sino metafísica.

Una realización que depende de un recreo de resistencias que escapa a la neta humanización y a la neta mundanización es el abordaje de $x$ realidad tanto como ella lo permita, no hay arbitrariedad a ultranza, no hay subjetivismo ni antropocentrismo, pero tampoco un puro objetivismo, sino resistencia de realidades que limitan los campos de abordaje. Si yo abordo topográficamente la superficie terrestre, habrá sin duda atributos impuestos por mí, pero algunos atributos estarán condicionados porque existe resistencia en las propiedades de la superficie terrestre misma; yo no podré decir, ahí donde hay un precipicio, que no lo hay, aunque es claro que puedo decir que el precipicio está al norte. Las condiciones topográficas me imponen ciertas propiedades ineludibles, aunque sobre ellas pueda atribuir característica subjetivas: la forma del suelo no depende de mí y es porque ella se me resiste que no puedo decir cualquier cosa de ella, que no puedo atribuirle arbitrariamente nada, por otra parte, que diga que está al Norte sí que es algo mío, porque el Norte y el Sur están arbitrariamente elegidos. Asimismo, el abordaje de la realidad animal no es una "antropomorfización a través de conceptos”, sino una realización conceptual que está puesta en función de la propia realidad animal y por ello es que, encontrando comunes denominadores propios de la realidad animal, el hombre mismo puede reconocerse en ésta y declararse como una especie más. Siendo el hombre eso que es, encuentra entonces que algo comparte con el resto de los animales.

Sólo entonces - una vez que el hombre ha encontrado denominadores comunes propios de la realidad animal reconociéndolos incluso en sí mismo- tiene sentido hablar in abstracto de "animalidad”, se entienda por ella lo que se entienda; sólo entonces tiene sentido que la animalidad quede definida por el discurso biológico, por ser la cualidad de aquellos que pueblan el reino de los animalia, aquellos eucariotas, heterótrofos, etc. Pues, sin embargo, antes de que el hombre encuentre en sí mismo comunes denominadores con algunas otras realidades, sean los animales, hablar siquiera de 
“animalidad” es un imposible y/o un sinsentido. Entender, así, lo que significa animalidad sólo es viable cuando la realidad humana ha recubierto sistemáticamente otras realidades no-humanas y ha encontrado en algunas de ellas algo que reconoce también como suyo, y esta viabilidad no es ya meramente animal.

Nótese que no es que el hombre se hiciera una autopsia, conceptual o física, para encontrar en él lo que sería el foco central de la realidad animal, sino que viendo lo que la realidad animal le permite ver fue que el hombre se encontró, también ahí, a sí mismo. Bien entendido, la realidad es en buena medida el espejo del hombre, de ahí que el conocimiento de ella y de sí sea, a la postre, especulativo. El hombre es una realidad allende la animalidad que, sin embargo, puede decirse animal x porque existe una realidad animal de la que forma parte realmente y la cual lo circunscribe realmente. Como antes hemos dicho respecto del cuerpo y el cerebro: no es que el hombre en virtud de poseer animalidad sea sensu stricto un animal, se trata más bien de que el hombre es animalesco.

El hombre es una realidad que tiene por propiedades, entre otras, la de ser animal y la de andar por encima. Propiedades que, como tales, le son propias (i.e., no son atributos, ni conceptos, ni precomprensiones, ni significaciones, ni simbolizaciones, ni proyecciones, etc.). El hombre anda por encima porque es por sobre las realidades que las aborda realmente. Sin embargo, es abordable también por sí mismo. El hombre puede abordarse incluso de diversas maneras: puede llamarse a sí mismo animal, puede clasificarse aquí y allá porque esencialmente no tiene clasificación. Él no está puesto en clasificación alguna, él pone las clasificaciones, y en ese poner clasificaciones puede, como segundo movimiento, ponerse a sí mismo dentro de varias de ellas. Andando por encima, puede incluso encontrarse un lugar "por debajo". ¿Quién si no el hombre mismo ha realizado la hoy afamada crítica al antropocentrismo?

Una vez matizado que el hombre es una realidad de realidades que no es animal sino más bien animalesca, entonces en vez de decir: el hombre es un animal $x$, un homo $x$ (pues aquí el homo es una especie 
animal), ${ }^{17}$ habría que decir: la especie homo o el animal $x$ es una propiedad biológicamente real del hombre.

6. Conclusión: algunas consecuencias éticas de pensar (o repensar) al hombre en clave metafísica

Para terminar, señalemos una propiedad fundamental del hombre que parece obvia y que de hecho lo es, pero que, por ser obvia, suele obviarse, es decir, o se olvida o se pretende oscura, a saber, que el hombre tiene por propiedad la de ser hombre. ${ }^{18}$

En algún momento, Heidegger justifica su concepto de Dasein (Heidegger, 2005: pp. 53-64 / §§ 9-11). Si bien él no lo considera un concepto, es, sin embargo, dentro de su propuesta, un concepto; un concepto que aspira a dejar de ser concepto. Heidegger se cuida de no querer decir con Dasein "hombre" o "humano" justo porque pretende salir de esa tradición conceptual concreta que preconcibe tras tales conceptos todo un horizonte de preconcepciones; pues cuando se dice hombre, se dice tras ello una determinada preconcepción de lo que pudiera ser aquello que llamamos hombre. Estas preconcepciones pueden ir desde el ser vivo dotado de razón (Aristóteles), ${ }^{19}$ hasta la persona (San Pablo); ${ }^{20}$ en cualquiera de las dos ya se piensa - previo al encuentro con el ente concreto que en cada caso efectivamente somos- lo que en cada caso deberíamos ser. Bien como bípedo sin plumas, bien como animal racional, ora como imagen y semejanza de Dios, o como poseedores del libre albedrío y dueños de nuestras

17 Me parece que los pensadores que parten del sujeto homo buscando el mejor adjetivo posible, hacen lo que aquellos que buscaban un mejor calificativo para animal. Bergson (homo faber), Sartori (homo videns), Huizinga (homo ludens), son ejemplos de pensadores que ven en una especie animal el foco del hombre.

18 Nótese que hemos mencionado a lo largo del texto diversas propiedades fundamentales del hombre que van constituyendo la fundamentalidad humana. Hemos hablado ya de ser corpóreo (y con ello, cerebral), animalesco, ser-hombre, próximamente diremos histórico, y (más relevante aquí) anda-por-encima, etc. Por decir algo.

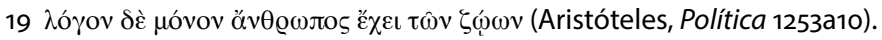

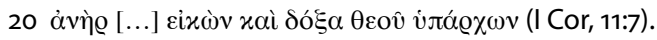


potestades; aquello que en cada caso somos es visto o - más propiamente- es pre-visto como bípedo sin plumas, animal racional, imagen y semejanza de Dios, poseedores de libre albedrío, etc. Justo en ese sentido, Heidegger quiere abandonar los conceptos de óv $\theta \varrho \omega \pi \mathrm{s}$, homo, homo naturalis, animal rationale, persona, entre otros, a fin de no precomprender y, por tanto, no prejuzgar, eso que en cada caso somos cada quien (Heidegger, 2008: pp. 32-53 / §§3-6). ${ }^{21}$ Podemos decir, a fuer de la invitación heideggeriana, que el Dasein precede al hombre; en el preciso sentido de que el Dasein no tiende a lo hombre o a lo humano, puesto que no tiende a nada sino que es lo que en cada caso (je schon) se es de facto, de tal forma que el Dasein, en tanto intento de alejamiento (o según se dice, rebasamiento) de las preconcepciones, es de hecho a-hombre o a-humano; es ajeno a los compromisos inherentes de lo hombre o lo humano.

Sin embargo, a mi parco entender, considero que una posición como esta, que a mi parecer muestra una pretendida asepsia de realidad, no solamente está desencarnada sino que, de hecho, es inhumana. Yo, por mi parte, he dicho que el hombre no es nuclearmente animal pero que, empero -y justo por ello se ha llamado a sí mismo animal $x$-el hombre es animalesco; el Dasein, por su parte, no diría en ningún caso que el hombre es, siquiera, hombre. Justo porque el Dasein pretende ser a-humano es que termina por ser in-humano. Es verdad que tras el concepto de hombre, como en el de óv $\theta \varrho \omega \pi$ o persona, etc., existe una precomprensión de ese ser concreto que

21 La hermenéutica de la facticidad sólo nos hace caer en la cuenta de que estamos precomprendidos; sin embargo, llegar hasta ahí es haber dado sólo un pequeño paso, pues si bien dice que efectivamente estamos precomprendidos, no cae en la cuenta de que sustantivamente debemos estar efectivamente precomprendidos. No nos dice tampoco que es por esa precomprensión que podemos caer en la cuenta de estar precomprendidos; no nos dice que esa precomprensión que llamamos hombre no sólo es efectivamente nosotros sino incluso es sustantivamente nosotros; pues es verdad que decirnos a nosotros mismos hombres es precomprendernos en toda una tradición que nos llama "hombres", pero esto es una verdad de perogrullo, pues no podríamos llamarnos de otra manera siendo no sólo efectiva sino sustantivamente seres en tradición, tradición que permite que en un momento dado se reconozca a la tradición misma como una precomprensión. El "rebasamiento" de las precomprensiones de Heidegger sólo es posible en un momento concreto del devenir de las precomprensiones que le permite hablar de "rebasamientos de precomprensiones". 
es llamado hombre, y es cierto que tras el concepto de animal racional se esconde toda una tradición filosófica y científica que lo ha pensado como tal, pero también es cierto que todo esto que está detrás de los conceptos no es algo que se esconda en ellos, sino que se muestra en ellos e incluso que los constituye; de hecho, esto les da su timbre particular. Todo eso que se preconcibe tras tales conceptos está efectivamente ahí, en ese ser del que se pretende no preconcebirlo. Si al hombre se le dice animal $x$ es porque de alguna manera sí es un animal x (ya dijimos de qué manera, que no es la nuclear), mas tratar de "des-preconcebir" al hombre que de facto está siempre concebido y preconcebido (como el mismo Heidegger aceptaría), es dejar al hombre en cuanto tal como un mero esquema vacío de contenido, es decir, deshumanizarlo. El hombre no es un Dasein, justo porque el "Dasein" concreto que llamamos hombre siempre está ya precomprendido y comprendido, sumergido y empapado de manera real y efectiva de lo que es ser hombre. El hombre existe realmente en relación con todo lo que de él se comprende, y ni en la abstracción es meritorio querer mostrarlo sin sus propiedades y atributos constitutivos. No existe ni ha existido ni existirá un ser puro, fuera de toda precomprensión, y pensarlo al menos como un ardid analítico a fin de estudiar lo que en cada caso somos, es usar una formalización de alguien que esencialmente está lleno de contenidos, es decir, usar una artificialidad. So pretexto de mera analiticidad, se desatiende, pues, que no hay formas sin contenidos ni contenidos sin formas.

No existe ser alguno ajeno a cualquier precomprensión, y pensar su existencia es sobresimplificar lo más propiamente humano, a saber, que su existencia está empapada de conceptos, de tamices, de historias, narrativas, colguijes y lastres que de una u otra manera lo hacen ser este o aquel hombre y que ni siquiera en la abstracción es pensable sin ellos. ${ }^{22}$ El Dasein es una abstracción que se disfraza de concretitud so pretexto de no precomprender lo que en cada caso somos, pero resulta que en cada caso que somos no sólo ya estamos precomprendidos por nosotros mismos y por los demás (lo

22 Por su parte, el que no exista algo puro no quiere decir que no pueden distinguirse de ellos sus propiedades (realidad) de sus atributos (sentido) (Zubiri, 1993: pp. 229 ss.). 
que hasta el mismo Heidegger acepta), sino que de hecho somos porque ya estamos precomprendidos, preconstituidos, formados, configurados, por nosotros mismos y por los demás. Precisamente ha sido en virtud de esto que el hombre, siendo animalesco, viéndose como animal se estima ulteriormente a sí mismo - para bien o para mal-como mera animalidad.

Esto es, el hombre es hombre y no Dasein, pues en su ser hombre se entiende toda la historicidad concreta y abstracta de ese ser que fue tanto ö $v \theta \varrho \omega \pi o s$ en Grecia, como civis y vir en Roma, como hijo de Dios en la Edad Media, como sujeto en la Modernidad, como libre y esclavo, como víctima y verdugo, como excelso y miserable... Justo es decirle al hombre, a esa realidad de realidades, hombre, pues, si no, lo estaríamos desgajando de su historicidad, propiedad inamovible de su realidad. Justo es decirle al hombre hombre, porque aquel que le dice de esa manera es también él un hombre (porque entre hombres se abarcan unos a otros), y está también siendo lanzado frente a sí mismo cada vez que invoca la humanidad de lo humano. Es decir, el hombre concreto no es un Dasein sin atributos, ${ }^{23}$ pues el hombre concreto está lleno de ellos, propios o atribuidos, que lo hacen ser el hombre que es. El hombre, pues, sumergido en la circunstancia ${ }^{24}$ como realidad de realidades, es un hombre al que le precede lo real, es un hombre que es real y al que se le resiste la realidad. Aquello

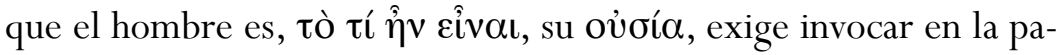
labra "hombre" todas las realidades constitutivas de su realidad. Por ello es que digo -permítaseme desarrollar la expresión en otra ocasión- que la sub-stancia pende de la circun-stancia.

$\mathrm{Si}$ es hombre, con toda la historicidad de lo que es ser humano, es porque existe una historicidad real en la que él se inserta de manera concreta. De hecho, si es hombre, es porque incluso es un animal $x$, porque su propiedad animal, netamente física, le posibilita el ser hombre. Es decir, su ser animal, histórico, cultural, etc., es

23 Los existenciarios del Dasein son igualmente vaciedades.

24 Como Ortega creyó: "Yo soy yo y mi circunstancia", pero, como Ortega ya no creyó, también soy mucho más. (Ortega y Gasset, 2005). 
real y está contenido en aquello que preconcebida y concebidamente llamamos así, hombre.

Su ser histórico es real. Su ser animal es real. Su ser humano es real. Y todo ello, todas estas realidades son propias del hombre. He aquí, pues, que lo fundamental en el hombre va constituyendo su fundamentalidad. Siendo una realidad constituida (y constituyente) de realidades es que puede abarcar la totalidad de éstas; anda por encima. Sin un aspecto histórico que lo posibilite a ser este hombre, el hombre sería siempre como un niño, ${ }^{25}$ descubriría el fuego cada vez que lo viera ajeno y jamás existiría la cultura, entidad abstracta y concreta que lo codifica como humano; gracias a su realidad cultural puede abarcar otras tantas realidades que ya no son culturales - por ejemplo, la ciencia (realidad cultural) aborda realidades materiales. Por su parte, sin un aspecto físico que lo posibilite a ser este hombre, el hombre no sería más que un animal, o quizá mera materia orgánica organizada según cadenas de carbono, sin esa glucosa que alimenta su cerebro físico que lo posibilita a crear ideas, quizá bastaría con los signos hormonales para ser específico al modo como lo son las abejas o los perros, pero gracias a esa estructura material tan suya, a esa realidad física que no le pertenece sino que le precede, ${ }^{26}$ puede abordar otras tantas realidades que ya no son meramente materiales - por ejemplo, con ayuda de su corteza cerebral puede generar símbolos. ${ }^{27}$

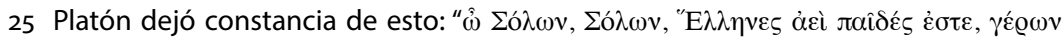

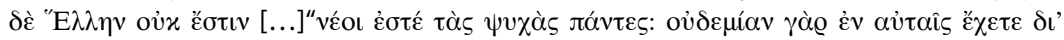

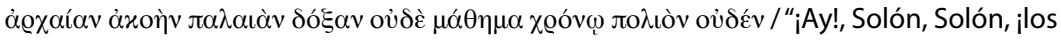
griegos seréis siempre niños!, ¡no existe el griego viejo! [...] Todos tenéis alma de jóvenes, pues no tienen creencias antiguas transmitidas por una larga tradición y carecéis de conocimientos encanecidos por el tiempo" (Timeo: 22b5-8).

26 En algún lugar he dicho, "cuando con el cerebro se piensa a la evolución con teorías científicas, el efecto piensa a la causa, mas esta precedencia del efecto es sólo epistemológica, pues ontológicamente existe un cerebro porque es producto de la evolución" (Sierra Lechuga, 2013a: p. 175).

27 Ambas realidades humanas que aquí expongo (que creo, por supuesto, que no son la únicas) también fueron reconocidas a su manera por M. Foucault del siguiente modo: "Si la cuestión del hombre fue planteada -en su especificidad de ser viviente y en su especificidad en relación con los seres vivientes-, debe buscarse la razón en el nuevo modo de relación entre la historia y la vida: en esa doble posición de la vida que la pone en el exterior de la historia como su entorno biológico y, a la vez, en el interior 
El hombre es animal racional, simbólico, político, social, y todo cuanto su resistencia como realidad permita, sapiens, sapiens sapiens, pero es todo eso porque no es sólo animal, porque de hecho su ser animal es una propiedad entre otras -y por lo tanto no es lo nuclear en él-que le posibilita ser hombre, pero no es su ser hombre. ${ }^{28}$ El hombre es una realidad de realidades porque realmente es capaz de abarcar, de algún modo, cualquier realidad que se le resista, resistiéndose él también a las otras realidades y a sí mismo, de aquí que en su relación con otros hombres esté llamado a responder por ellos siempre (i.e. a ser responsable) (Sierra Lechuga, 2014). La propiedad obvia de ser hombre le llama a ser humano, esto es, a ser humanista y humanitario, pues cada vez que está con otros hombres éstos aparecen siempre como reales, nunca como meras ilusiones, objetos de juego, abstracta fuerza de trabajo, imaginarios conejillos de indias, quimeras. ${ }^{29} \mathrm{Y}$, junto con ello, también aparece que todo lo que esos otros hombres hacen lo hacen por motivos reales, pues a ellos les aparecen como reales aun cuando

de la historicidad humana, penetrada por sus técnicas de saber y de poder" (Foucault, 2011: p.134).

28 Creer que lo animal es primero a lo hombre es dejar de ver en el hombre a un hombre concreto y ver no más que la vida. En el hombre, diríamos, no existe la vida, sino lo vivo, lo viviente, un ser humano con vida, pero no la vida in abstracto. Al inicio de este trabajo citábamos cómo Hegel entendía al animal como "la vida que existe como vida", la vida que vive, pues bien, en ese sentido el hombre es, en efecto, la vida que vive pero que además se vive vivientemente como una realidad de por sí viva. Anteponer la vida al hombre es matarlo; la vida del hombre por encima del hombre mismo paradójicamente lo mata. Se pone a la vida por encima de la dignidad. M. Foucault es muy consciente de ello cuando afirma: "Desde el siglo pasado, las grandes luchas que ponen en tela de juicio el sistema general de poder ya no se hacen en nombre de un retorno a los antiguos derechos ni en función del sueño milenario de un ciclo de los tiempos y una edad de oro. Ya no se espera más al emperador de los pobres, ni el reino de los últimos días, ni siquiera el restablecimiento de justicias imaginadas como ancestrales; lo que se reivindica y sirve de objetivo es la vida, entendida como necesidades fundamentales, esencia concreta del hombre, realización de sus virtualidades, plenitud de lo posible" (Foucault, 2011: p.135).

29 Podría decírseme que bajo esta concepción, el psicópata no es hombre pues no responde a este llamado ético. Nada más lejos de lo que yo pensaría; en tanto que hombre, realidad de realidades (que por muy "desprendido de la realidad-fáctica" que esté, la forma de la aparición -sea lo que sea que se le aparezca- es el carácter de realidad), en tanto que hombre, posee dicho llamado a responder, otra cosa (y otro problema-serio-) es que no responda. 
pudiéramos creer que los contenidos de dichas realidades son nimiedades; motivos reales que, en cuanto tales, ameritan ser considerados abierta, concienzuda, responsable y respetuosamente, pues más allá de que los contenidos de tales motivos sean materialmente significativos, son motivos efectivamente reales que mueven a hombres concretamente reales; de carne, hueso,,$^{30} \mathrm{y}$ mucho más.

Así pues, siendo realidad de realidades, al hombre le es exigible ${ }^{31}$ una actitud despierta para procurar entender las realidades del otro y de lo otro, sensata para entender sus propios límites, incansable en la búsqueda de la verdad de lo real pero dócil en la exposición de los resultados siempre parciales que vaya adquiriendo en dicha búsqueda; le es exigible una actitud libre para proclamar la verdad cuando haya que hacerlo pero modesta para no imponer lo que a él le gustaría que fuese verdadero; es exigible al hombre real, de carne, hueso y más, una actitud indulgente con los que yerran y a la vez arrepentida ante sus propios yerros, imparcial en sus juicios pero siempre abierta a los juicios de los otros hombres, apta para escuchar la realidad, que mienta a gritos su presencia, y humilde para no considerarse su autor, ordenador o creador, para no ensalzarse ni enseñorearse frente a ella, que le ha dado su carácter más legítimo y digno: ser realidad de realidades $\mathrm{y}$ no más bien estéril humo, polvo, sombra, nada... ${ }^{32}$

30 Parafraseando una expresión de Miguel de Unamuno (Unamuno, 2000).

31 Las siguientes exigencias están profundamente inspiradas (e incluso son paráfrasis) de lo que considero una oración de la inteligencia, oración que sin querer ha sido creada como tal por el teólogo José María Cabodevilla: “Danos, Señor, una inteligencia despierta para procurar entender tus verdades y a la vez sensata para comprobar y entender sus propios límites, batalladora en la investigación y mansa en la exposición, indulgente con los que yerran y contrita ante sus propios yerros, imparcial en sus juicios y siempre acatadora de los tuyos, una inteligencia libre para proclamar tu verdad y modesta para no imponer sus propias verdades, apta para escucharte a ti, que eres la Sabiduría, y humilde para no desertar de ti, que has querido explicarnos las cosas como las explicaría un sabio a sus nietos" (Caboevilla, 1986: p. 66).

32 Respondiendo a la pregunta filosófica de Leibniz (pourquoi il y a plutôt quelque chose que rien?) y a su interpretación entificada de Heidegger (warum ist überhaupt Seiendes und nicht vielmehr Nichts?) respondo poéticamente en el texto parafraseando a Luis de Góngora en el final de su soneto "Mientras por competir", que también fue parafraseado por Sor Juana Inés de la Cruz en el soneto CXLV intitulado "A su retrato". 


\section{REFERENCIAS BIBLIOGRÁFICAS:}

Bergson, Henri. 2006. Materia y memoria. Buenos Aires: Cactus.

Bergson, Henri. 2007. La evolución creadora. Buenos Aires: Cactus.

Buber, Martin. 2008. ¿Qué es el hombre? México: Fondo de Cultura Económica.

Buber, Martin. 2000. Yo y Tú y otros ensayos. Lilmod: Buenos Aires.

Cabodevilla, José María. 1986. Discurso del Padre Nuestro. Madrid: Biblioteca de Autores Cristianos.

Callan, Hilary. 1978. Etología y sociedad. México: Fondo de Cultura Económica.

Cassirer, Ernst. 2001. Antropología filosófica. México: Fondo de Cultura Económica.

Foucault, Michel. 2011. Historia de la sexualidad 1. La voluntad de saber. México: Siglo XXI.

Hegel, G.W.F. 2008. Filosofía real. México: Fondo de Cultura Económica.

Heidegger, Martin. 2005. El ser y el tiempo. México: Fondo de Cultura Económica.

HeIDEgGer, Martin. 2008. Ontología (Hermenéutica de la facticidad). Madrid: Alianza.

Holder, Rodney. 2008. Nothing but atoms and molecules? Cambridge: The Faraday Institute.

JASPERs, Karl. 2006. La filosofía. México: Fondo de Cultura Económica.

KAHLER, Erich. 2004. Historia universal del hombre. México: Fondo de Cultura Económica.

KöHLER, Wolfgang. 1940. Dynamics in psychology, New York: Liveright Publishing Corporation.

KÖHLER, Wolfgang. 1959. "Gestalt Psychology Today” en American Psychologist, 14, pp. 727-734.

LÉvi-STrauss, Claude. 1995. Antropología estructural. Barcelona: Paidós.

Malinowsky, Bronislaw. 1993. Magia, ciencia y religión. Barcelona: Editorial PlanetaDe Agostini.

Marx, Karl. 1982. El Capital. México: Fondo de Cultura Económica.

MonOD, Jacques. 2000. El azar y la necesidad. Barcelona:TusQuets.

Ortega y Gasset, José. 2005. "Historia como sistema”, en Obras completas. Madrid: Taurus.

Platón. 1903. “Timaeus”, Platonis Opera, ed. John Burnet. Oxford: Oxford University Press.

SCHeler, Max. 2000. El puesto del hombre en el cosmos. Barcelona: Alba.

SCHÖDINGER, Erwin. 2007. Mente y materia. Barcelona: TusQuets. 
Siñverberg, Robert. 1980. El hombre antes de Adán. México: Diana.

Sierra Lechuga, Carlos. 2013a. "Dios y la Realidad Fásica: Aplicación de las distinciones entre la consistencia lógica, la existencia objetual y la subsistencia metafísica” en Apuntes Filosóficos, v. 22, n. 42, pp. 170-201.

Sierra Lechuga, Carlos. 2013b. “Por qué decimos que la Realidad es una y que, además, tiene ventanas distintas?” en César Navarro y Gonzalo Chamorro (eds.) Ciencia y Fe: dos ventanas una realidad. Guatemala: Sociedad Educativa Latinoamericana para Fe y Ciencia, pp. 23-37.

Sierra Lechuga, Carlos. 2013c. "Asir gradualmente la realidad: para un principio de correspondencia ontológico-epistemológico” en Atualidade Teológica, ano XVII, fasc. 45 , pp.553-571.

Sierra Lechuga, Carlos. 2014. "Persona y clonación humana, Partes I, II, III. ¿Qué hay a propósito de la posibilidad de que algún clon humano sea considerado persona?" en Razón y Pensamiento Cristiano,19 de febrero, 27 de marzo y 23 de abril, respectivamente. Disponible en línea.

TAPIA, Ricardo. 2010. Las células de la mente. México: Fondo de Cultura Económica.

Unamuno, Miguel de. 2000. Del sentimiento trágico de la vida. Buenos Aires: Errepar.

Zubiri, Xavier.1964. “El origen del hombre” en Revista de Occidente, 17, pp. 146-173.

ZuBiri, Xavier. 1975. "El problema teologal del hombre”, en Antonio Vargas-Machuca. Teología y mundo contemporáneo: homenaje a K. Rahner. Madrid: Ediciones Cristiandad, p. 55-64.

ZuBIRI, Xavier. 1980. Inteligencia sentiente: inteligencia y realidad. Madrid: Alianza.

Zubiri, Xavier. 1981. "Reflexiones teológicas sobre la eucaristía" en Estudios escolásticos, 56, pp. 41-59.

ZuBIRI, Xavier. 1993. Sobre el sentimiento y la volición. Madrid: Alianza.

Zubiri, Xavier. 2001. Los problemas fundamentales de la metafísica occidental. Madrid: Alianza.

ZuBIRI, Xavier. 2005. El hombre: lo real y lo irreal. Madrid: Alianza.

ZuBIRI, Xavier. 2005. “QQué es investigar?” en The Xavier Zubiri Review, 7, pp. 5-7.

ZuBIRI, Xavier. 2006. El hombre y la verdad. Madrid: Alianza. 